\title{
Experimental Investigation on Atomization and Dustfall Characteristics of Combined Nozzles for Shearer External Spray in Fully Mechanized Coal Mining Face
}

\author{
Qian Wang, ${ }^{1,2}$ Ruixin Song, ${ }^{1,2}$ Junpeng Wang, ${ }^{1,2}$ Cuicui Xu $\mathbb{D}^{1,2}$ Gang Zhou, $^{1,2}$ \\ and Jiayuan Wang ${ }^{3}$ \\ ${ }^{1}$ College of Safety and Environmental Engineering, Shandong University of Science and Technology, Qingdao 266590, China \\ ${ }^{2}$ State Key Laboratory of Mining Disaster Prevention and Control Co-Founded by Shandong Province and the Ministry of \\ Science and Technology, Shandong University of Science and Technology, Qingdao 266590, China \\ ${ }^{3}$ Energy Heating Limited Company of Qingdao West Coast Utility Group, Qingdao 266400, China
}

Correspondence should be addressed to Cuicui Xu; xucuicui519@163.com

Received 26 April 2021; Accepted 3 November 2021; Published 15 December 2021

Academic Editor: Qingsheng Bai

Copyright (c) 2021 Qian Wang et al. This is an open access article distributed under the Creative Commons Attribution License, which permits unrestricted use, distribution, and reproduction in any medium, provided the original work is properly cited.

\begin{abstract}
To explore the dustfall effect of combined nozzles used in a fully mechanized mining face, Phase Doppler Interferometry (PDI) system was used to test 6 types of high-efficiency atomizer under $8 \mathrm{MPa}$. A new nozzle group of nozzles $2 \#, 3 \#$, and $5 \#$ is selected by atomization experiment. The atomization experiment and field application test of the preferred nozzle are performed. The experiment and field application results show that, with the spray pressure of $8 \mathrm{MPa}$, when the distance in the nozzle group is $200 \mathrm{~mm}$ and the angle change is 10 degrees, the atomization effect is the best. Under the optimal parameters, the average dustfall rates of the entire and respirable dust are $81.82 \%$ and $79.96 \%$, respectively, which are $23.49 \%$ and $20.75 \%$ higher than those of the traditional shearer.
\end{abstract}

\section{Introduction}

In recent years, the mining level of mechanization and automation of coal mines in China has been gradually improved [1-3], and the disasters caused by the production process of coal mines have become increasingly prominent [4-6]. In particular, the dust hazards in underground working areas have seriously threatened the safety of mine production and the physical and mental health of miners [7-9]. According to measurements, with no dust-proof measures, the dust production of a coal mining face is as high as $60 \%$ of the total dust of the mine [10-12]. When a shearer cuts coal, the instantaneous total dust concentration in some coal mines is higher than $4000-6000 \mathrm{mg} / \mathrm{m}^{3}$ $[13,14]$. Even if dust-proof measures are taken, the working environment of most coal mining faces and the total dust and exhaust dust powder on the downwind side of the shearer remain very bad. The dust concentration instantaneously reaches $500 \mathrm{mg} / \mathrm{m}^{3}$ and $200 \mathrm{mg} / \mathrm{m}^{3}[15,16]$. Those dust concentrations far exceeded the upper limit stipulated in the national safety regulations. Cutting dust is the main dust produced in a coal mining face. Therefore, it is particularly important to effectively control the coal cutting dust production in the coal mining face $[17,18]$. At present, most scholars at home and abroad mainly focus on two aspects: spray numerical simulations and spray dustfall experiments [19-22]. In the numerical simulation of sprays, $\mathrm{Xu}$ et al. used the VOF method to simulate the internal flow field of X-swirl pressure nozzle and found that the swirl angle and outlet diameter are two important parameters affecting the spray field velocity [23]. On the basis of VOF-LES method, Yu et al. introduced the adaptive mesh refinement (AMR) method to predict the breakup of liquid core in the process of primary atomization [24]. 
However, the aforementioned studies mostly focused on the internal flow field of the nozzle and did not involve the atomization distribution characteristics of the external spray field of the nozzle. In an experiment with spray and dust suppression, Charinpanitkul and Tanthapanichakoon studied the atomized droplet size distribution of different types of nozzles and their effects on the dustfall rate of different sizes of dust [25]. Based on the self-designed nozzle atomization test platform, Cheng Weimin and Zhou et al. performed atomized droplet size testing of several commonly used nozzles under different pressures in the coal mining face and studied the atomization effect of the high-pressure spray atomization droplet size [26]. Wang et al. used a self-designed spray dust reduction experimental system to study the quantitative relationship between the diameter and the atomization parameters of commonly used pressure nozzles [27, 28]. However, most of the above studies were aiming at single characteristics of the nozzles, which resulted in large randomness in the selection of nozzles.

Although the above scholars have performed systematic research on two aspects, spray numerical simulations and spray dust reduction experiments, none of these analyses concerned the selection of different types of nozzle combinations, atomization parameters of multiple nozzles, and atomization and dust suppression effects of multiple nozzle groups. Therefore, based on the self-built spray and dust simulation experiment system, 6 types of nozzles of different types were selected for experimental study. The distribution law of droplet size distribution and the optimization of atomization parameters between different nozzles in fully mechanized coal face under different types of nozzle combinations are studied in detail and applied in fully mechanized coal mining face. This work provides a reference for improving the efficiency of shearer external spray and dust suppression.

\section{Experimental System and Scheme}

2.1. Experiment System. To clearly and accurately analyze the distribution characteristics of the external spray atomization characteristics of shearers in a fully mechanized working face, the macroscopic and microscopic characteristics of the droplet field were measured based on Phase Doppler Interferometry (PDI) test system and dustfall indoor simulation system. The experimental system is mainly composed of a phase Doppler laser interferometer (PDI200MD), a mine tunnel simulator, a K45-6 type mine energy-saving ventilator, a spray device, a SAG-410 dust aerosol generator, and a control and data acquisition device. The simulation roadway is mainly composed of two parts. They are the inlet diffuser with the shape of pyramid and the cuboid experimental section with the length, width, and height of $3.0 \mathrm{~m}$, $3.0 \mathrm{~m}$, and $2.5 \mathrm{~m}$, respectively. The air inlet is a circle with a diameter of $1.4 \mathrm{~m}$, and the air outlet is a rectangle with a section of $3.0 \mathrm{~m} \times 2.5 \mathrm{~m}$. Except that the air inlet and air outlet are not closed, the other 8 surfaces are sealed with $1 \mathrm{~cm}$ thick plexiglass. The layout of the test system is shown in Figure 1.

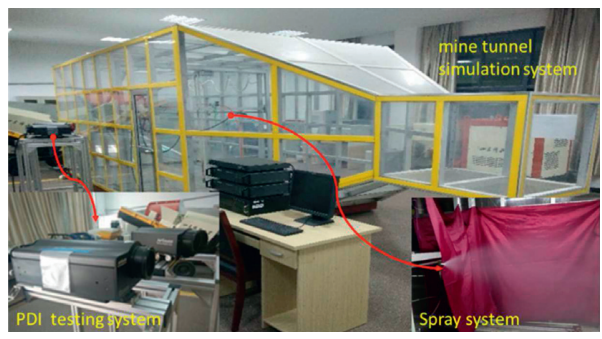

FIGURE 1: Doppler laser interferometric spray experiment system.

2.2. Selection of Experimental Nozzles. Based on the investigation of major coal mines and shearer nozzle manufacturers, 6 types of external spray nozzles for shearers with better dustfall effects $[29,30]$ were selected and numbered by the Roman number of the nozzle. The specific objects are shown in Figure 2. Nozzle 1\# is a $1.8 \mathrm{~mm}$ linear hollow cone nozzle, nozzle $2 \#$ is a solid cone wide-angle nozzle with a diameter of $2.0 \mathrm{~mm}$, and nozzle $3 \#$ is the cross opening with an aperture of $2.4 \mathrm{~mm}$. The swirl centrifugal mixed solid conical with an orifice diameter of $3.0 \mathrm{~mm}$ is named nozzle $4 \#$, mixed solid conical nozzle with $2.0 \mathrm{~mm}$ orifice is named nozzle \#5, and solid conical fan nozzle with $2.8 \mathrm{~mm}$ orifice is named nozzle $6 \#$.

2.3. Experimental Scheme. To accurately obtain the droplet size and droplet velocity distribution in the spray field, the droplet size distribution at different positions of the spray field was measured by using the Doppler laser interferometer PDI200MD spray dustfall simulation experiment system. According to the actual wind speed of fully mechanized face in Jianzhuang Coal Mine being $1 \mathrm{~m} / \mathrm{s}$, in order to make the experiment more accurate, the wind speed of the simulated tunnel will be kept at $1 \mathrm{~m} / \mathrm{s}$. To more clearly analyze the distribution of droplet characteristics, measuring points were set up in the simulated roadway, among which 9 measuring points were distributed on three different planes. The coordinates of the nine points in $\mathrm{mm}$ are $\mathrm{A}(500,0), \mathrm{B}$ $(1500,600), \mathrm{C}(1500,0), \mathrm{D}(1500,-600)$, E $(2500,1200), \mathrm{F}$ (2500, 600), G (2500, 0), H (2500, -600), and I (2500, -1200). The layout of the measuring points in the droplet field is shown in Figure 3; experimental process is shown in Figure 4.

\section{Performance of Single Nozzle in a Fully Mechanized Coal Face}

3.1. Macroscopic Characteristics and Droplet Size Distribution. The investigation and study on the fully mechanized coal face in Jianzhuang Coal Mine showed that the nozzle pressure used at the site was $8 \mathrm{MPa}$. So, the experiment is carried out under $8 \mathrm{MPa}$. The results are shown in Table 1 and Figure 5.

(1) According to the macroparameters of atomization characteristics of the nozzle, the atomizing angle of different nozzles is in the following order $5 \#>2 \#>6 \#>4 \#>1 \#>3 \#$. The range of different nozzles is $3 \#>4 \#>6 \#>1 \#>2 \#>5 \#$. Compared with 


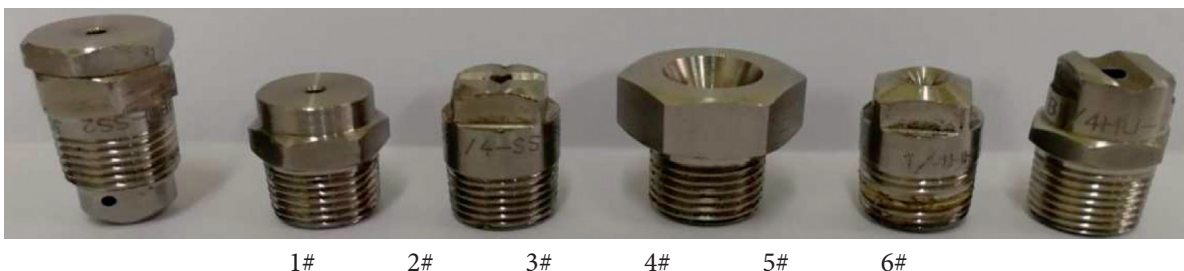

Figure 2: Nozzles used in the experiment.

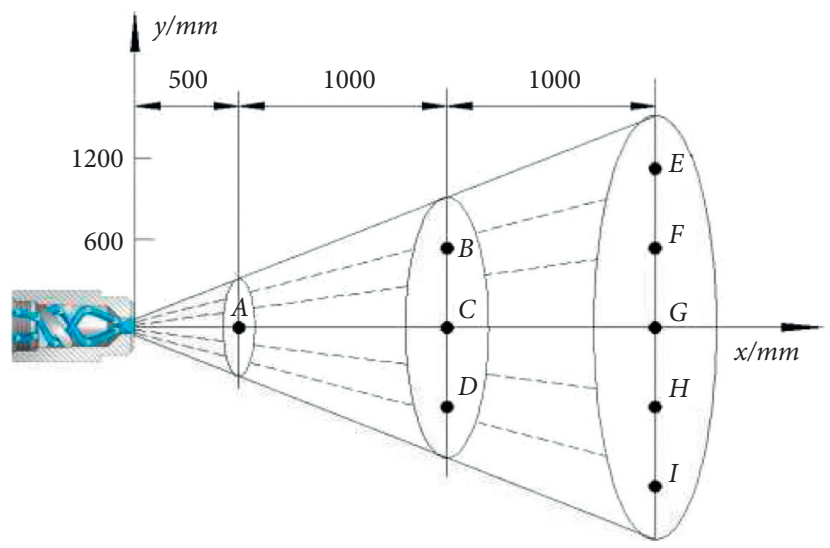

FIGURE 3: Layout of the measuring points of the droplet field.
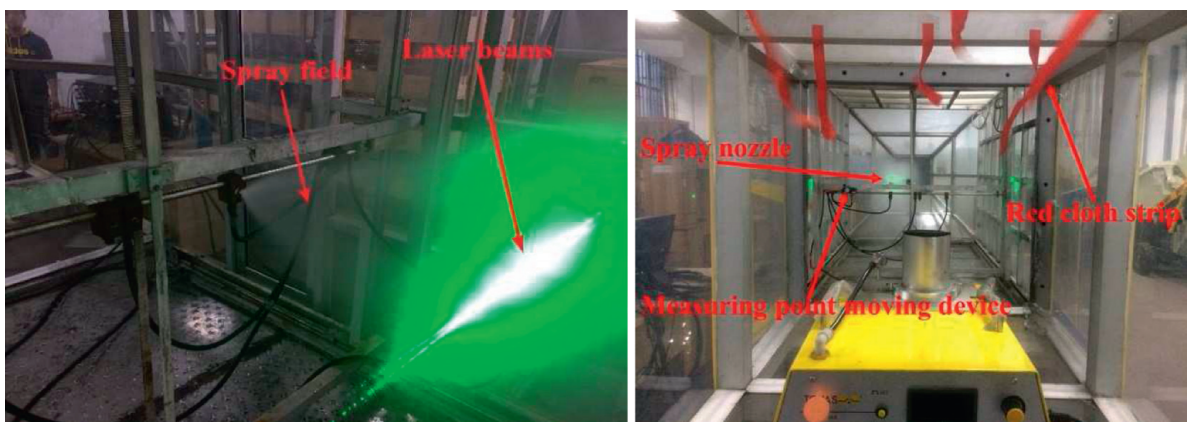

FIgURE 4: Experimental diagram of nozzle atomization.

TABle 1: Macroscopic characteristic parameters of different nozzles and mean value of the microdroplet size.

\begin{tabular}{|c|c|c|c|c|c|c|c|}
\hline \multirow{2}{*}{ Nozzles number } & \multicolumn{2}{|c|}{ Macroscopic characteristics parameters } & \multicolumn{5}{|c|}{ Spray droplet size } \\
\hline & Atomization angle $\left({ }^{\circ}\right)$ & Effective range $(\mathrm{m})$ & $D_{0.1} / \mu \mathrm{m}$ & $D_{0.5} / \mu \mathrm{m}$ & $D_{0.9} / \mu \mathrm{m}$ & $D_{32} / \mu \mathrm{m}$ & $D_{43} / \mu \mathrm{m}$ \\
\hline $1 \#$ & 75 & 3.87 & 27.44 & 57.18 & 117.30 & 48.32 & 68.23 \\
\hline $2 \#$ & 88 & 3.65 & 21.13 & 48.36 & 97.31 & 39.40 & 63.64 \\
\hline $3 \#$ & 69 & 4.73 & 30.01 & 69.34 & 133.27 & 52.94 & 80.59 \\
\hline $4 \#$ & 73 & 4.36 & 38.48 & 87.46 & 155.81 & 67.94 & 99.42 \\
\hline $5 \#$ & 94 & 3.60 & 18.93 & 46.06 & 86.26 & 36.81 & 54.88 \\
\hline $6 \#$ & 80 & 4.15 & 30.61 & 71.60 & 134.75 & 63.48 & 85.16 \\
\hline
\end{tabular}

the above macroscopic atomization parameter data, the range of atomization and the angle of atomization are two negative atomizing parameters. In addition, because of the difference in nozzle structure, the droplet kinetic energy is transformed into axial and radial kinetic energy at the nozzle, which results in the negative correlation difference between the atomization angle and the range.
(2) The average droplet size, volume probability, and cumulative volume distribution of droplets from different nozzles show that the droplet size distribution is consistent with the normal distribution under the spray pressure of $8 \mathrm{MPa}$ and the droplet size dispersion of different nozzles is different. The standard deviation of the normal distribution of nozzle droplet size of $1-6 \#$ nozzle is $52.947,35.186$, 

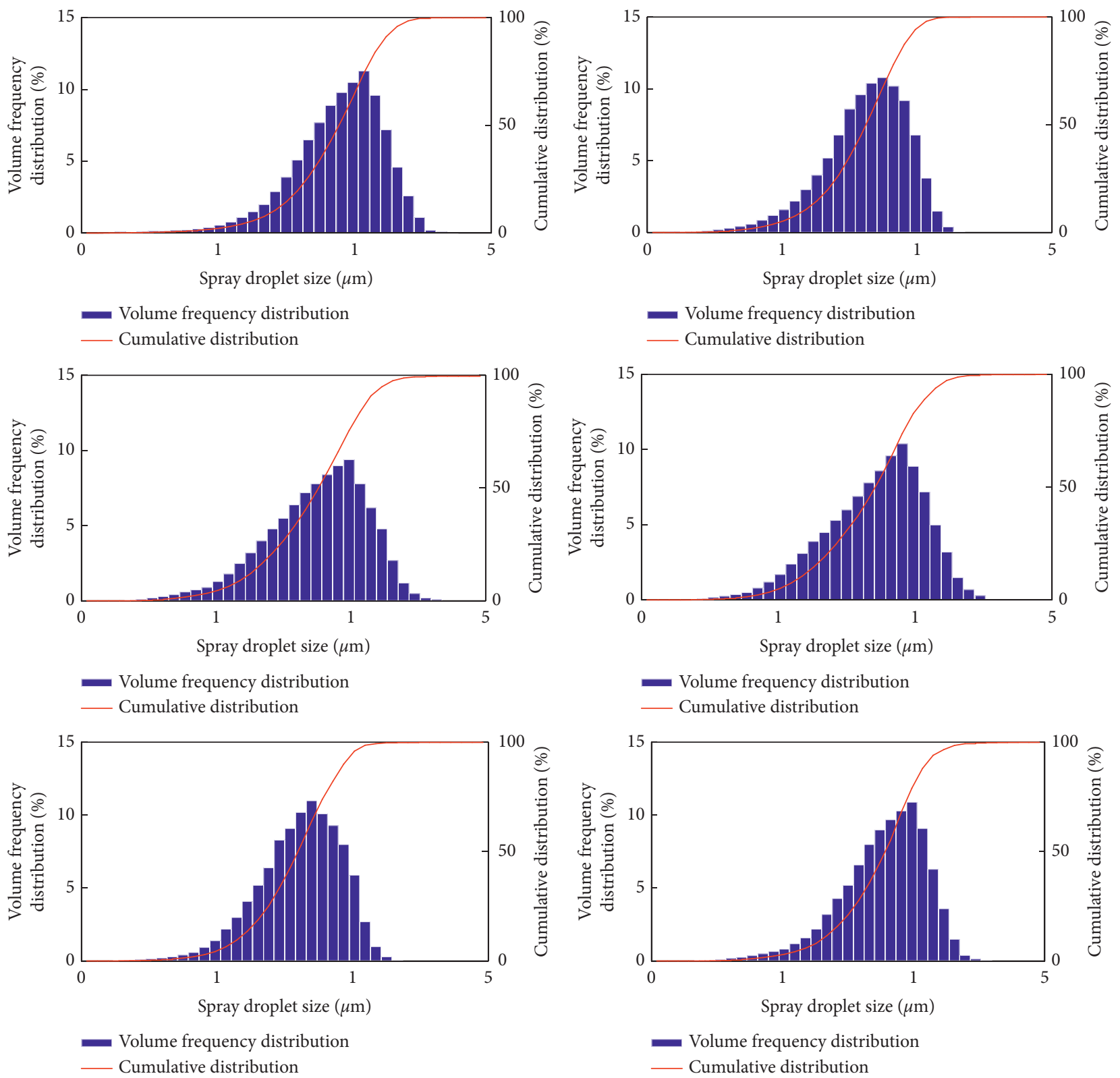

Figure 5: Sketch of the droplet size, volume distribution, frequency distribution, and cumulative distribution of droplets for different nozzles.

43.051, 58.542, 83.723, and 66.312 in order. The standard deviation of normal distribution of droplet size can measure the dispersion degree of droplet. The larger the standard deviation of the normal distribution, the more dispersed the droplet distribution. The smaller the standard deviation of the normal distribution, the more uniform the droplet distribution. The more uniform the droplet size distribution, the higher the dust reduction efficiency. It can be seen that the order of the dispersion degree of the droplet size distribution of the six nozzles is $5 \#>6 \#>4 \#>1 \#>3 \#>2 \#$.
3.2. Droplet Velocity Distribution. The velocity distribution of different measuring points is shown in Table 2 and Figure 6.

Figure 6 shows the following:

(1) The experimental data for the droplet velocity of different nozzles show that the droplet field of the nozzle shows different trends in the axial and radial directions: for the axial velocity, the axial velocity of the droplet gradually decreases with the increase in axial distance of the nozzle, and the fluctuation of the axial velocity of the droplet gradually decreases with the increase in radial distance; for the radial velocity, 
TABLE 2: Mean droplet velocity at different nozzles.

\begin{tabular}{|c|c|c|c|c|c|c|c|c|c|c|}
\hline \multirow{2}{*}{ Velocity vector } & \multirow{2}{*}{ Nozzles number } & \multicolumn{9}{|c|}{ Droplet velocity $(\mathrm{m} / \mathrm{s})$} \\
\hline & & $\mathrm{A}$ & $\mathrm{B}$ & $\mathrm{C}$ & $\mathrm{D}$ & $\mathrm{E}$ & $\mathrm{F}$ & G & $\mathrm{H}$ & I \\
\hline \multirow{6}{*}{ Axial velocity } & $1 \#$ & 36.652 & 25.991 & 33.594 & 27.293 & 18.406 & 19.926 & 26.716 & 22.886 & 25.575 \\
\hline & $2 \#$ & 32.774 & 24.693 & 28.834 & 25.426 & 16.397 & 18.071 & 23.356 & 20.659 & 22.099 \\
\hline & $3 \#$ & 47.468 & 32.693 & 40.215 & 35.057 & 23.256 & 25.653 & 30.499 & 26.659 & 27.471 \\
\hline & $4 \#$ & 46.226 & 30.499 & 38.527 & 32.903 & 20.408 & 23.373 & 29.148 & 25.512 & 26.576 \\
\hline & $5 \#$ & 30.962 & 21.314 & 25.776 & 22.925 & 16.134 & 19.065 & 23.695 & 20.294 & 21.815 \\
\hline & $6 \#$ & 41.587 & 28.265 & 38.201 & 29.324 & 19.179 & 21.884 & 27.254 & 23.573 & 25.127 \\
\hline \multirow{6}{*}{ Radial velocity } & $1 \#$ & 1.265 & 2.443 & 1.635 & 2.668 & 2.323 & 2.101 & 1.840 & 2.315 & 2.703 \\
\hline & $2 \#$ & 1.789 & 3.743 & 2.566 & 4.029 & 3.769 & 3.393 & 3.047 & 4.072 & 4.337 \\
\hline & $3 \#$ & 1.218 & 2.317 & 1.755 & 2.634 & 2.236 & 1.936 & 1.657 & 1.990 & 2.303 \\
\hline & $4 \#$ & 1.586 & 2.980 & 2.189 & 3.245 & 2.858 & 2.560 & 2.406 & 3.036 & 3.807 \\
\hline & $5 \#$ & 1.870 & 3.305 & 2.419 & 3.730 & 4.155 & 3.486 & 3.116 & 4.267 & 4.675 \\
\hline & $6 \#$ & 1.783 & 2.946 & 2.278 & 3.220 & 3.684 & 3.171 & 2.808 & 3.542 & 4.292 \\
\hline
\end{tabular}

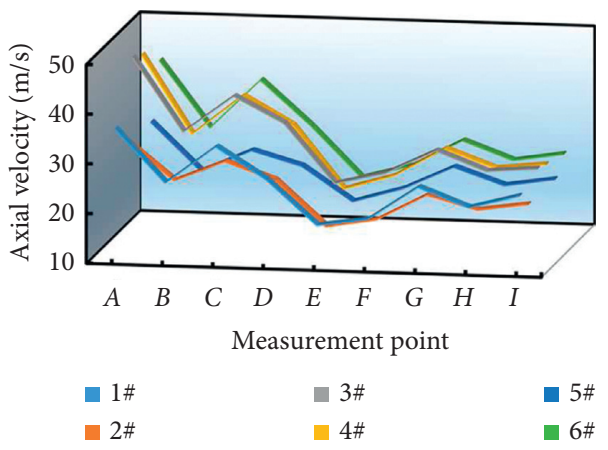

(a)

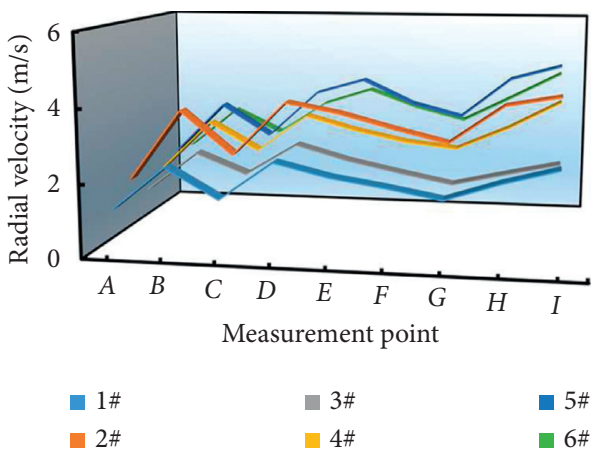

(b)

FIgURe 6: Droplet velocity curve of different nozzles. (a) Axial velocity. (b) Radial velocity.

the axial distance increases. With the increase in radial distance, the radial velocity increases in varying degrees, but the radial velocity is smaller than the axial velocity of the droplets.

(2) The change rate of the droplet velocity in the axial direction of different nozzles is as follows: in the axial direction of A, C, and G, the average decrease rates of the axial and radial velocities of different nozzles are $36.15 \%$ and $17.63 \%$, respectively. The axial and radial velocities have opposite change trends in both axial and radial directions. The velocity gradually decreases from the center to the surroundings, and the radial velocity gradually increases from the center to the surroundings. Taking E, F, G, H, and I with a distance of $3000 \mathrm{~mm}$ from the nozzle as an example, the average reduction rate of the axial velocity is $42.84 \%$, and the average growth rate of the radial velocity is $32.37 \%$. The above droplet velocity variation and droplet field macroscopic characteristic parameter show that the axial velocity plays a major role in the range of the fog field, and the radial velocity plays a key role in the coverage of the spray field.

(3) The change rates of the axial velocity and radial velocity show that the axial velocity plays a leading role in the effect of the radial velocity on the fog field, and the axial velocity of the droplet is basically maintained at $20 \sim 30 \mathrm{~m} / \mathrm{s}$, which is conducive to capturing the respirable dust. The radial velocity plays a decisive role in the coverage of the spray field, while the droplet radial velocity basically remains at $1.5 \sim 4.5 \mathrm{~m} / \mathrm{s}$. Intermediately, this velocity is the main factor that affects the size of the atomization angle.

\section{Atomization Characteristics of Combined Nozzles}

4.1. Nozzle Optimization for Shearer External Spray. The Winner 99 microparticle image analyzer was used to measure the dust particles produced during the upwind cutting in the area of shearer of No. 3 upper 901 fully mechanized mining face in Jianzhuang Coal Mine. The distribution characteristics of dust particles in the area of a fully mechanized mining face and the downwind side of the shearer were obtained. According to the characteristics of dust production in the shearer area of the fully mechanized mining face, five dust sampling points were set up: front drum of the shearer, driver of the shearer, back drum of the shearer, downwind side of the shearer at $10 \mathrm{~m}$, and downwind side of the shearer at $20 \mathrm{~m}$; the number of 
measuring points is $1,2,3,4$, and 5 , respectively. When the flow field in the working space is relatively stable, the AKFC92A mine dust sampler is placed at the measuring points for sampling. The height of the measuring point is the height of the respiratory zone. The dust is sampled and dried. Each measurement point was measured three times; the average value was measured. The volume frequency and dust concentration of the dust particle size distribution at different locations and distribution zones in the production area of the fully mechanized mining face are shown in Table 3; the histogram of dust particle size distribution is shown in Figure 7.

The experimental results in Figure 7 show that the particle size distribution of dust in different production areas of the fully mechanized mining face varies and that the particle size distribution is basically $0-20 \mu \mathrm{m}$. The particle size of dust in each dust-measuring area has the following order: rear drum of the shearer $>$ front drum of the shearer $>$ coal mining machine. The average particle size of dust was calculated from the data of different measuring points (11.26 $\mu \mathrm{m}, 8.85 \mu \mathrm{m}, 13.03 \mu \mathrm{m}, 3.19 \mu \mathrm{m}$, and $2.70 \mu \mathrm{m})$. Hence, the large particles of dust are settled by gravity in the dust migration process with the air flow, the smaller particles are further moved with the air flow, and the proportion of exhaled dust in the total dust gradually increases.

According to the distribution law of dust particle size in different dust-producing areas of a fully mechanized mining face and according to previous studies, the best relationship between the droplet size and the dust particle size captured is that the droplet size is $8-10$ times of the dust particle size $[31,32]$, which is conducive to dustfall. According to the droplet size and droplet velocity of different nozzles, three kinds of nozzles meeting the droplet size distribution requirements were selected from six kinds of nozzles. 5\# nozzles are suitable for short distance, large atomizing angle, and smaller droplet size as the inner nozzle for shearer external spray. 3\# nozzle is also suitable for long distance, small atomizing angle, large droplet size, and large droplet velocity as the outside spray nozzles for shearers. 2\# nozzle is suitable for medium distance, large atomizing angle, droplet size, and droplet velocity as the center nozzle.

\subsection{Distribution of Atomization Parameters of the Combined} Nozzles. The atomization characteristics of the selected nozzles were obtained at different distances and spray angles (shown in Table 4 and Figure 8). The angle of the nozzle spray changed from inside to outside. When the angle changed to 5 degrees, the angle of the nozzle was -5 degrees, 0 degrees, and 5 degrees from inside to outside, and the distance between the nozzle and the nozzle group is expressed in terms of $d$ and $\alpha$.

Table 4 and Figure 8 show the following:

(1) When the distance between the nozzles is fixed, the droplet size of the nozzle droplet field first decreases and subsequently increases with the increase in angle $\alpha$. When $\alpha=10$ degrees, the droplet size is minimal. For example, when $d=150 \mathrm{~mm}$, the droplet size parameters of the nozzle decreased from $(37.02 \mu \mathrm{m}$,
$90.35 \mu \mathrm{m}, 161.28 \mu \mathrm{m}, 78.34 \mu \mathrm{m}$, and $97.14 \mu \mathrm{m})$ at $\alpha=0$ degree to $(36.90 \mu \mathrm{m}, 89.65 \mu \mathrm{m}, 158.79 \mu \mathrm{m}$, $77.86 \mu \mathrm{m}$, and $394.22 \mu \mathrm{m})$ at $\alpha=10$ degree; then, it increased to $(35.46 \mu \mathrm{m}, 87.02 \mu \mathrm{m}, 154.51 \mu \mathrm{m}$, $75.39 \mu \mathrm{m}$, and $95.51 \mu \mathrm{m})$ at $\alpha=15$ degree. The results show that, with the increase in $\alpha$, the overall distribution of droplet size is more uniform, but when $\alpha$ increases to a certain limit, the droplet is not easy to break up, and the distribution of droplet size is more dispersive, which is not conducive to dust capture.

(2) When the inclination of the nozzle group is constant, the droplet size of the nozzle droplet field first decreases and subsequently increases with the increase in $d$. When $d=200 \mathrm{~mm}$, the droplet size is minimal. For example, when $\alpha=10$ degrees, the droplet size decreased from $(34.27 \mu \mathrm{m}, 85.13 \mu \mathrm{m}, 149.64 \mu \mathrm{m}$, $73.25 \mu \mathrm{m}$, and $88.73 \mu \mathrm{m})$ at $d=150 \mathrm{~mm}$ to $(31.15 \mu \mathrm{m}$, $79.34 \mu \mathrm{m}, 137.57 \mu \mathrm{m}, 69.73 \mu \mathrm{m}$, and $82.08 \mu \mathrm{m})$ at $d=200 \mathrm{~mm}$; then, it increased to $(35.01 \mu \mathrm{m}$, $86.90 \mu \mathrm{m}, 157.13 \mu \mathrm{m}, 79.60 \mu \mathrm{m}$, and $90.65 \mu \mathrm{m})$ at $d=250 \mathrm{~mm}$. A larger distance between the nozzles corresponds to a weaker effect between the droplet fields. However, when the distance between the nozzles is short, the effect between the droplet fields is greater, which is not conducive to the breakup of droplets. When the distance increases to a better equilibrium value, a smaller droplet size is conducive to the breakup of the droplets.

(3) When the distance between the nozzles and the angle of the nozzles increase, the probability of droplet collision and fragmentation increases, the droplet size decreases as a whole, and the velocity distribution is uniform. However, when the droplet collision and fragmentation increase to a certain extent, the probability of reunion increases, and the droplet size distribution becomes more dispersed, which is not conducive to dust capture. The above data show that when the distance between the nozzles is $200 \mathrm{~mm}$ and the angle is 10 degrees, the droplet size and velocity distribution of the droplet field are the best, and the condition is more suitable to capture dust particles.

\section{Field Application}

The present study conducts field testing for the external spray atomization dust reduction application test at the shearer outside of the 905 fully mechanized mining face at Jianzhuang Coal Mining Co., Ltd., Shandong Energy ZaoZhuang Mining Group. The fully mechanized mining face has a working face height of $3200 \mathrm{~mm}$; the working face wind speed is $1.05 \mathrm{~m} / \mathrm{s}$; it uses a G500/1130-WD AC traction shearer to cut coal; the shearer provides a spray pressure of $8 \mathrm{MPa}$; the working face of the original shearer spray and interrack spray and other dust-proof measures are available. In the field test, the experimental 2\#, 3\#, and 5\# nozzle groups were selected as the external spraying group of the shearer. The spray unit was designed and developed, and the 
TABLE 3: Particle size distribution, volume frequency, and dust concentration at different positions of the fully mechanized coal mining face.

\begin{tabular}{lccccccc}
\hline \multirow{2}{*}{ Measurement point } & \multicolumn{3}{c}{ Frequency of dust particle size range } & \multicolumn{2}{c}{ Dust concentration $\left(\mathrm{mg} / \mathrm{m}^{3}\right)$} \\
& $0 \sim 2.5 \mu \mathrm{m}$ & $2.5 \sim 4 \mu \mathrm{m}$ & $4 \sim 10 \mu \mathrm{m}$ & $10 \sim 20 \mu \mathrm{m}$ & $\geq 20 \mu \mathrm{m}$ & Total dust concentration & Respirable dust concentration \\
\hline 1\# & 8.63 & 19.20 & 25.78 & 28.92 & 17.47 & 674.2 & 309.5 \\
2\# & 12.54 & 26.09 & 29.01 & 21.16 & 11.20 & 627.0 & 263.8 \\
3\# & 7.30 & 13.97 & 27.46 & 34.12 & 17.15 & 826.1 & 344.7 \\
4\# & 26.33 & 31.68 & 22.13 & 16.26 & 3.60 & 431.3 & 205.2 \\
5\# & 29.53 & 35.09 & 19.53 & 12.47 & 3.38 & 385.9 & 171.6 \\
\hline
\end{tabular}

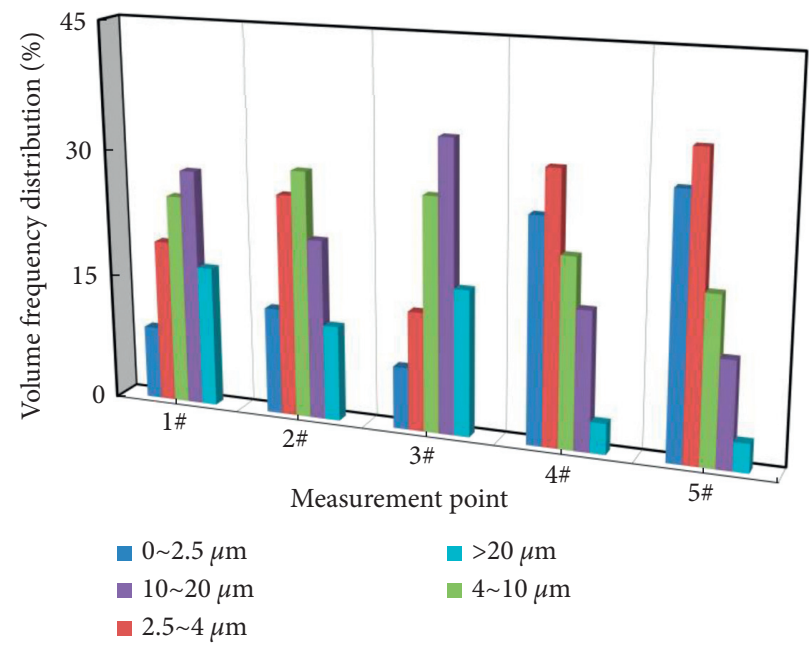

FIGURE 7: Frequency distribution of the dust particle size in the fully mechanized coal mining face.

TABLE 4: Mean values of the atomization characteristic parameters of spray group under different spacings and angle changes.

\begin{tabular}{|c|c|c|c|c|c|c|c|c|}
\hline \multirow{2}{*}{$d(\mathrm{~mm})$} & \multirow{2}{*}{$\alpha\left({ }^{\circ}\right)$} & \multicolumn{5}{|c|}{ Spray droplet size } & \multicolumn{2}{|c|}{ Droplet velocity } \\
\hline & & $\mathrm{D}_{0.1} / \mu \mathrm{m}$ & $\mathrm{D}_{0.5} / \mu \mathrm{m}$ & $\mathrm{D}_{0.9} / \mu \mathrm{m}$ & $\mathrm{D}_{32} / \mu \mathrm{m}$ & $\mathrm{D}_{43} / \mu \mathrm{m}$ & $\mathrm{V}_{\mathrm{x}} / \mathrm{m} / \mathrm{s}$ & $V_{y} / \mathrm{m} / \mathrm{s}$ \\
\hline \multirow{4}{*}{150} & 0 & 37.02 & 90.35 & 161.28 & 78.43 & 97.14 & 25.49 & 1.34 \\
\hline & 5 & 36.90 & 89.65 & 158.79 & 77.86 & 94.22 & 24.85 & 1.41 \\
\hline & 10 & 34.27 & 85.13 & 149.64 & 73.25 & 88.73 & 23.56 & 1.46 \\
\hline & 15 & 35.46 & 87.02 & 154.51 & 75.39 & 95.51 & 23.13 & 1.55 \\
\hline \multirow{4}{*}{200} & 0 & 35.97 & 85.20 & 154.16 & 75.81 & 87.63 & 27.69 & 1.45 \\
\hline & 5 & 33.24 & 81.73 & 143.73 & 73.25 & 85.81 & 26.85 & 1.50 \\
\hline & 10 & 31.15 & 79.34 & 137.57 & 69.73 & 82.08 & 25.40 & 1.58 \\
\hline & 15 & 34.52 & 83.58 & 145.31 & 72.36 & 89.45 & 24.72 & 1.66 \\
\hline \multirow{4}{*}{250} & 0 & 41.85 & 97.21 & 171.60 & 85.73 & 96.91 & 29.16 & 1.53 \\
\hline & 5 & 39.46 & 93.47 & 169.04 & 83.36 & 98.48 & 27.72 & 1.59 \\
\hline & 10 & 35.01 & 86.90 & 157.13 & 79.60 & 90.65 & 26.34 & 1.63 \\
\hline & 15 & 36.33 & 91.52 & 165.79 & 82.09 & 93.14 & 25.51 & 1.69 \\
\hline
\end{tabular}

dust concentration was measured by the atomizing dust suppression effect of the nozzle group at 10 degrees of different nozzle spacings. The field application test chart of the shearer external spray device is shown in Figure 9. Because the shearer external spray is mainly aiming at the dust production during coal cutting process, $1,2,3,4$, and 5 measuring points were located on the downwind side of the shearer's front cylinder at $5 \mathrm{~m}, 10 \mathrm{~m}, 20 \mathrm{~m}, 30 \mathrm{~m}$, and $40 \mathrm{~m}$, respectively.

When the flow field in the working space is relatively stable, the AKFC-92A mine dust sampler is placed at the measuring points for sampling. The height of the measuring point is the height of the respiratory zone. The dust is sampled and dried. Each measurement point was measured three times; the average value was measured. The results are shown in Table 5 . Table 5 shows that when the traditional coal shearer is sprayed outside, only the coal and dust sources are cut off, and the average dust and dusting rates at different measuring points of the fully mechanized coal mining face are $62.48 \%$ and $62.21 \%$, respectively. When the new type of shearer outside the spray unit is opened, the total dust and dust concentration of the 5 measuring points first 


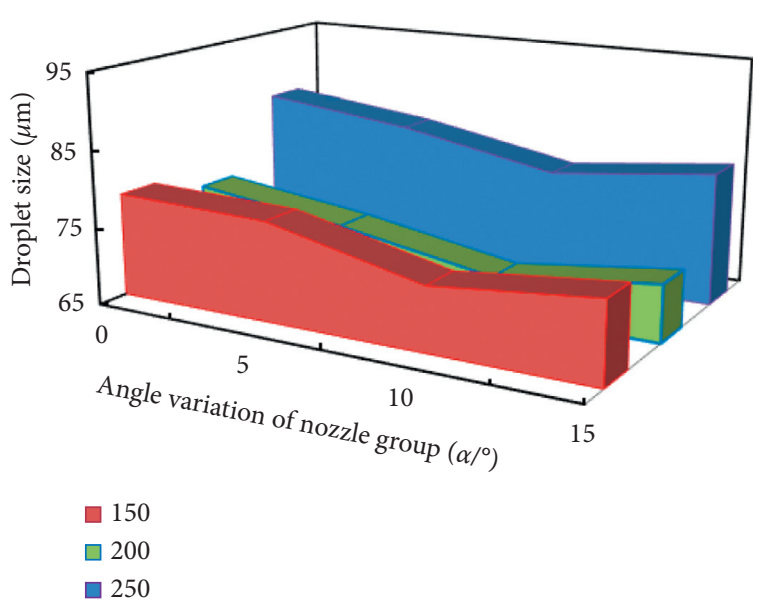

(a)

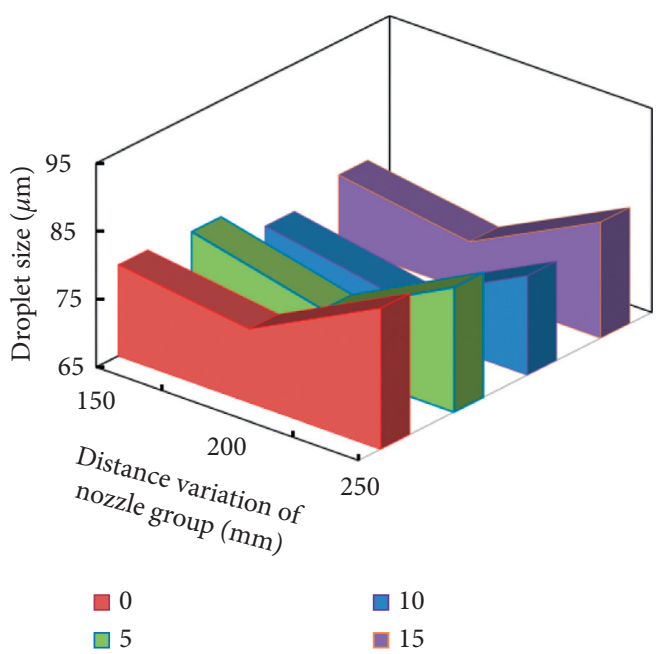

(b)

FIGURE 8: Changes in the droplet size at different spacings and angles of the nozzle groups. (a) Curve of the change in droplet size with nozzle group angle. (b) Curve of the change in droplet size with nozzle group distance.

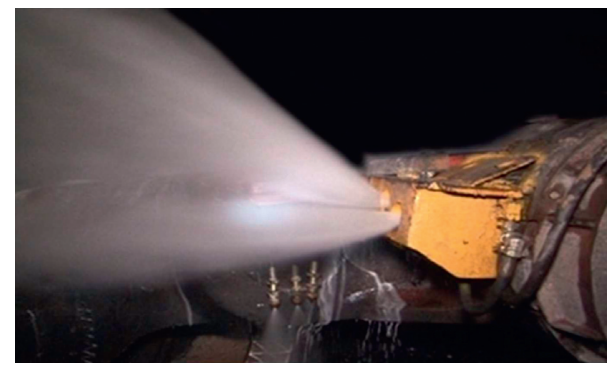

FIGURE 9: Field application diagram of the shearer external spray unit.

decrease and subsequently increase with the increase in distance between the external spraying units of the shearer. The dust concentration at $5 \mathrm{~m}$ of the downwind side of the front drum of the shearer decreased from $227.5 \mathrm{mg} / \mathrm{m}^{3}$ and $115.4 \mathrm{mg} / \mathrm{m}^{3}$ at the distance $d=150 \mathrm{~mm}$ to $148.5 \mathrm{mg} / \mathrm{m}^{3}$ and $70.3 \mathrm{mg} / \mathrm{m}^{3}$ at the distance $d=200 \mathrm{~mm}$; then, it increased to $179.2 \mathrm{mg} / \mathrm{m}^{3}$ and $84.9 \mathrm{mg} / \mathrm{m}^{3}$ at $d=250 \mathrm{~mm}$. After calculation, the average values of total dust and dustfall changed from $70.17 \%$ to $69.72 \%$ at $d=150 \mathrm{~mm}$; they were $85.82 \%$ and $82.96 \%$ when the new spray group was applied in the field, and the dustfall rate decreased to $76.03 \%$ and $76.87 \%$ when $d=250 \mathrm{~mm}$ was applied at $d=200 \mathrm{~mm}$. Thus, when the angle of the external spray unit is 10 degrees, the dustfall effect is the best when the distance between the 


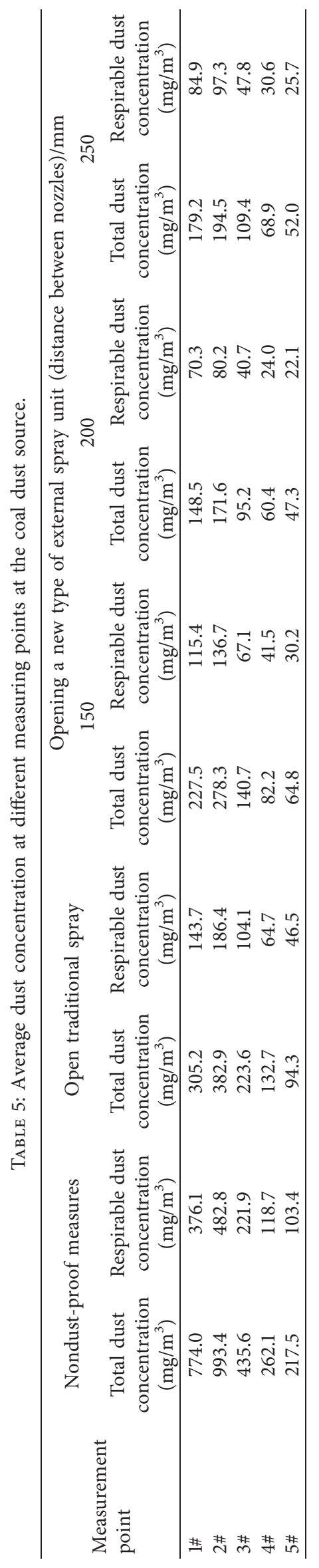


nozzles is $200 \mathrm{~mm}$, and the total dust and dust removal rate of the traditional coal shearer atomizer group increase by $23.34 \%$ and $20.75 \%$, respectively.

\section{Conclusion}

(1) According to the analysis of the macroatomization characteristic parameters of different nozzles, there is a negative correlation between the spray angle and the range of the spray nozzle when the spray pressure is constant. Moreover, the droplet size distribution conforms to the normal distribution. A more concentrated dispersion corresponds to a more uniform droplet size distribution, which can improve the efficiency of the dust suppression.

(2) The droplet velocity of different atomization parameters of different nozzles shows that axial velocity plays a major role in capturing dust and is the main factor that affects the range of the spray field. The radial velocity has little effect on dust capture, but the radial velocity determines the coverage of the spray field, and the radial velocity is the main factor that affects the atomization angle.

(3) The experiment of atomization parameters of the combined nozzles shows that, with the increase in distance $d$ and angle a between the nozzles, the probability of droplets colliding and breaking up in the overlapping area between the nozzles increases. When the distance between the nozzles is $200 \mathrm{~mm}$ and the angle of nozzle group changes to 10 degrees, the distributions of droplet size and velocity are the best, and it is more suitable to capture dust particles. According to the field application test of the shearer external spraying unit on the fully mechanized face, when the interval between the outside shearers is $200 \mathrm{~mm}$, the dust removal efficiency of the fully mechanized mining face is the best. The field application effect is basically identical to the experimental results, which has theoretical guiding significance for the optimization design of the external spray unit of a fully mechanized mining face.

\section{Data Availability}

No data were used to support this study.

\section{Conflicts of Interest}

The authors declare that they have no conflicts of interest regarding this work.

\section{Acknowledgments}

This work was financially supported by the National Natural Science Foundation of China (Grant nos. 52004150, 51774198, and 51904171), the Qingchuang Science and Technology Project of Universities in Shandong Province, China (Grant no. 2019KJH005), the Science and Technology Project of Qingdao City (Grant no. 20-3-4-2-nsh), the
Taishan Scholars Project Special Funding in Shandong Province, China (Grant no. ts20190935), the National Key Research and Development Program of China (Grant no. 2017YFC0805202), and the Natural Science Foundation of Shandong Province, China (Grant no. ZR2019BEE067).

\section{References}

[1] Q. Zhou, G. Xu, Y. Chen, B. Qin, Z. Zhao, and C. Guo, "The development of an optimized evaluation system for improving coal dust suppression efficiency using aqueous solution sprays," Colloids and Surfaces A: Physicochemical and Engineering Aspects, vol. 602, 2020.

[2] Y. Wang, Z. Jiang, J. Chen, J. Chen, and M. Wang, "Study of high-pressure air curtain and combined dedusting of gas water spray in multilevel ore pass based on CFD-DEM," Advanced Powder Technology, vol. 30, no. 9, 2019.

[3] S. Hu, G. Feng, X. Ren et al., "Numerical study of gas-solid two-phase flow in a coal roadway after blasting," Advanced Powder Technology, vol. 27, no. 4, pp. 1607-1617, 2016.

[4] T. Zhang, D. Jing, S. Ge, J. Wang, X. Chen, and S. S. Ren, "Dust removal characteristics of a supersonic antigravity siphon atomization nozzle," Advances in Mechanical Engineering, vol. 12, no. 12, 2020.

[5] F. Han, D. Wang, J. Jiang, and X. Zhu, "A new design of foam spray nozzle used for precise dust control in underground coal mines," International Journal of Mining Science and Technology, vol. 26, no. 2, pp. 241-246, 2016.

[6] Y. Yu, H. Yang, W. Cheng, C. Gao, L. Zheng, and Q. Xin, "Effect of acetic acid concentration on functional group and microcrystalline structure of bituminous coal," Fuel, vol. 288, Article ID 119711, 2021.

[7] H. Yao, H. Wang, Y. Li, and L. Jin, "Three-dimensional spatial and temporal distributions of dust in roadway tunneling," International Journal of Coal Science \& Technology, vol. 7, no. 1, pp. 88-96, 2020.

[8] Q. Zhou, B. Qin, Ma Dong, and N. Jiang, "Novel technology for synergetic dust suppression using surfactant-magnetized water in underground coal mines," Process Safety and Environmental Protection, vol. 109, 2017.

[9] B. Kong, E. Wang, and Z. Li, "The effect of high temperature environment on rock properties-an example of electromagnetic radiation characterization," Environmental Science and Pollution Research, vol. 25, no. 29, pp. 29104-29114, 2018.

[10] H. Yang, Y. Yu, W. Cheng, J. Rui, and Q. Xu, "Influence of acetic acid dissolution time on evolution of coal phase and surface morphology," Fuel, vol. 286, Article ID 119464, 2021.

[11] M. Wu, X. Hu, Q. Zhang, D. Xue, and Y. Zhao, "Growth environment optimization for inducing bacterial mineralization and its application in concrete healing," Construction and Building Materials, vol. 209, pp. 631-643, 2019.

[12] M. R. Shahan, "The design of a laboratory apparatus to simulate the dust generated by longwall shield advances," International Journal of Coal Science \& Technology, vol. 6, no. 4, pp. 577-585, 2019.

[13] B. Sun, W. Cheng, J. Wang, and H. Wang, "Effects of turbulent airflow from coal cutting on pollution characteristics of coal dust in fully-mechanized mining face: a case study," Journal of Cleaner Production, vol. 201, pp. 308-324, 2018.

[14] Z. Xiu, N. Wen, D. Chen et al., "Numerical simulation study on the coupling mechanism of composite-source airflow-dust field in a fully mechanized caving face," Powder Technology, vol. 356, 2019. 
[15] L. Chen, P. Li, G. Liu, W. Cheng, and Z. Liu, "Development of cement dust suppression technology during shotcrete in mine of China-A review," Journal of Loss Prevention in the Process Industries, vol. 55, pp. 232-242, 2018.

[16] M. Jia, Y. Fu, Y. Yuan, W. Hongmin, S. Sun, and J. Li, "Migration law of respirable dust on a super-long fully mechanized double-shearer working face," International Journal of Mining Science and Technology, vol. 26, no. 6, pp. 1109-1115, 2016.

[17] L. Qin, P. Wang, S. Li et al., "Gas adsorption capacity changes in coals of different ranks after liquid nitrogen freezing," Fuel, vol. 292, Article ID 120404, 2021.

[18] L. Qin, P. Wang, S. Li et al., "Gas adsorption capacity of coal frozen with liquid nitrogen and variations in the proportions of the organic functional groups on the coal after freezing," Energy \& Fuels, vol. 35, no. 2, pp. 1404-1413, 2021.

[19] B. Sun, W. Cheng, J. Wang, H. Wang, and Y. Ma, "Development of Venturi negative-pressure secondary dedust device and application of local spray closure technique," Advanced Powder Technology, vol. 30, no. 1, pp. 42-54, 2019.

[20] Z. Liu, H. Yang, W. Wang, W. Cheng, and L. Xin, "Experimental study on the pore structure fractals and seepage characteristics of a coal sample around a borehole in coal seam water infusion," Transport in Porous Media, vol. 125, no. 2, pp. 289-309, 2018.

[21] X. Liu, S. Liu, and P. Tang, "Coal fragment size model in cutting process," Powder Technology, vol. 272, pp. 282-289, 2015.

[22] H. Yu, W. Cheng, H. Peng, and Y. Xie, "An investigation of the nozzle's atomization dust suppression rules in a fullymechanized excavation face based on the airflow-droplet-dust three-phase coupling model," Advanced Powder Technology, vol. 29, no. 4, pp. 941-956, 2018.

[23] J. Wang, C. Xu, Y. Zhang, and G. Zhou, "Numerical study of the effect of geometric parameters on the internal flow of a pressure nozzle for dustfall," Advanced Powder Technology, vol. 32, no. 5, 2021.

[24] H. Yu, Y.-C. Jin, W. Cheng, X. Yang, X. Peng, and X. Yao, "Multiscale simulation of atomization process and droplet particles diffusion of pressure-swirl nozzle," Powder Technology, vol. 379, 2021.

[25] T. Charinpanitkul and W. Tanthapanichakoon, "Deterministic model of open-space dust removal system using water spray nozzle: effects of polydispersity of water droplet and dust particle," Separation and Purification Technology, vol. 77, no. 3, pp. 382-388, 2011.

[26] G. Zhou, W. Nie, W. M. Cheng, and G. Wang, "Influence regulations analysis of high-pressure atomization dust-settling to dust particle's microscopic parameters in fully mechanized caving coal face," Journal of China Coal Society, vol. 39, pp. 2053-2059, 2014.

[27] P. Wang, C. Tian, R. Liu, and J. Wang, "Mathematical model for multivariate nonlinear prediction of SMD of X-type swirl pressure nozzles," Process Safety and Environmental Protection, vol. 125, pp. 228-237, 2019.

[28] P. Wang, Y. Li, R. Liu, and Y. Shi, "Effects of forced-to-exhaust ratio of air volume on dust control of wall-attached swirling ventilation for mechanized excavation face," Tunnelling and Underground Space Technology, vol. 90, pp. 194-207, 2019.

[29] J. Liu, M. B. Su, Q. L. Li, and Z.-G. Wang, "Analysis of geometric parameters influence on pressure swirl injector performance based on VOF interface tracking method," Journal of Aerospace Power, vol. 26, pp. 2826-2833, 2011.
[30] M. Z. Li and G. R. Zhao, "High pressure spray nozzle design and parameter optimization based on finite element simulation analysis," Journal of China Coal Society, vol. 40, pp. 279-284, 2015.

[31] S. Yang, W. Nie, S. Lv et al., "Effects of spraying pressure and installation angle of nozzles on atomization characteristics of external spraying system at a fully-mechanized mining face," Powder Technology, vol. 343, pp. 754-764, 2019.

[32] H. Wang, Y. Du, X. Wei, and X. He, "An experimental comparison of the spray performance of typical water-based dust reduction media," Powder Technology, vol. 345, pp. 580-588, 2019. 